\title{
PRINCIPALS' WORK STORIES WITHIN NEO-LIBERAL SCHOOL REFORM
}

\author{
John Rafferty \\ Charles Sturt University, Albury, Australia \\ E-mail: jrafferty@csu.edu.au \\ Tuija A. Turunen \\ University of Lapland, Rovaniemi, Finland \\ E-mail: tuija.turunen@ulapland.fi
}

\begin{abstract}
The purpose of this research is to investigate the work stories of four principals as they implement a neoliberal school reform program in their schools. Work stories were defined as explanatory frameworks the principals used to explore the effects of the program. The work stories included several sub-themes, story lines. Discourse analysis was used to identify the work stories and the story lines within semi-structured interviews with the principals. The results indicate that the principals constructed the neo-liberal school reform program as a new, better school culture. The new culture needed to be promoted with enough firmness to establish social norms and to ensure conformity of teacher behaviour. To ensure the implementation of the program, the principals positioned themselves as corporate leaders or sporting coaches with little reference to educational considerations. The work stories positioned the teachers in their schools as 'managed professionals' with diminished trust and respect as teaching and educational professionals. Analysing work stories helps to understand what is happening to particular individuals within particular institutions at particular times. Within the neo-liberal landscape, there is a temptation to think that the social relations, meanings and assumptions of schooling are no longer problematic. Discourse analysis provides one way to see behind these temptations and provides an alternative analysis on neo-liberal reform programs.
\end{abstract}

Key words: neo-liberalism, school reform, work stories, managed professionals, discourse analysis.

\section{Introduction}

The values, meanings and power inherent in neo-liberal reform programs create and perpetuate powerful forms of discourse that characterize the projects themselves, evoke loyalty and commitment (Rafferty, 2010). This leads to the creation and perpetuation of 'officially' sanctioned ways of thinking. Proponents of reform programs may argue that such sanctions are a necessary feature of school reform programs and provide a focus for energy and activism, for winning people's support, and for conveying to parents and the wider school community a sense of purposeful action and rational planning. However, these neo-liberal discourses bring changes to schools far beyond those anticipated and planned for. Despite increased pressure to adopt neo-liberal reforms, there are few studies that evaluate the effect of reform from the perspective of those who implement them. Previous studies have investigated for example educators' interpretations of neo-liberal reforms in Australia and Finland (e.g.Turunen \& Rafferty, 2013; Rafferty, 2010). These studies demonstrate how the voices of teachers can be reduced to background noise against a dominant discourse. 
John RAFFERTY, Tuija A. TURUNEN. Principals' work stories within neo-liberal school reform

PROBLEMS

OF EDUCATION

IN THE $21^{\text {st }}$ CENTURY

Volume 64,2015

76

\section{Neo-liberal Landscape in Education}

School reform dominates the political agenda of most advanced economies, including the United States of America, the United Kingdom, and Australia. In these countries there has been an unprecedented political investment in expanding bureaucratic control of the development and delivery of educational services (Apple, 2004; Desimone, 2002; Elliott \& Maclennan, 1994; Gruenewald, 2004; Harris \& Chrispeels, 2006; Jeffrey, 2002; Matthews, O’Mahony, \& Barnett, 2006). Scholastic competence is understood as the gateway to socio-economic security for the individual and the bulwark of the economy on which society is built (Ball, 2004). There is intense interest in knowing whether schools are delivering value for money, how effective schooling is, and how better outcomes for whole populations and entire school systems can be achieved (Fullan, 2007, 2009; Fullan, Hill, \& Crevola, 2006; Levin, 2010; Levin \& Fullan, 2008). Increasingly, high quality evidence of effectiveness is becoming the primary determinant of school funding allocations in many countries. Schools are under pressure to produce quantifiable statistical results which enable comparison with other schools and which can then be used to justify funding. In the UK Higher Standards Better Schools for All. White Paper (Her Majesty's Government, 2006) highlights an increasing reliance on accountability measures as a means of improving education. Similarly, the Australian federal government's Smarter Schools - National Partnership program (Department of Education, 2008) and the National Assessment Program - Literacy and Numeracy, NAPLAN (Australian Curriculum Assessment and Reporting Authority ACARA, 2008) emphasise improved school and student performance through greater transparency and accountability. In these countries the pressure to be accountable and to demonstrate improvement has resulted in governments, school administrators, principals and parents prioritizing the accurate, reliable and defensible collection, dissemination and utilization of information above all else (Elmore, 2000; Levin, 2010). Increasingly, reform programs generated from the neo-liberal paradigm place an emphasis on improved student outcomes as a way of measuring success.

Neo-liberal school reform models are predicated upon the notion that if lasting changes are to occur, teachers must share beliefs in fundamental education issues. The role of the principal within this framework is to manage the change process and challenge, stimulate and motivate teachers, regardless of how threatening or uncomfortable the experience may be (Popkewitz, 2008). The use of "hard" quantitative data is regarded as an essential foundation of reform programs and the teachers' instructional behaviours become the target of explicit attention. Neo-liberal reform programs also refer to the importance of collaboration, but do not necessarily regard consensus as being part of collaboration (Fullan, Bertani, \& Quinn, 2004).

The study reported in this paper moves toward identifying the realities of the implications of reform programs through the work stories of four principals who identified their schools as "CLaSS schools". In this paper we use The Children's Literacy Success Strategy program, CLaSS, in the Victorian Catholic Education system as an example of a neo-liberal reform program in Australia. CLaSS (Hill \& Crévola, 2001) was developed outside the education sector and presents a detailed program for implementation at school and classroom levels. The program is legitimized through the methodological heritage of School Effectiveness Research (SER) commenced in the late 1970s (Goldstein \& Myers, 1997). That is, the characteristics of effective schools are widely accepted and are considered to be beyond questioning because of the esteem in which the positivistic and quantitative evaluation techniques employed by the SER tradition are held within the academic and wider community. Drawing on the SER tradition, CLaSS articulates a set of beliefs and assumptions about teaching and learning through a structured reform process (Hill \& Crévola, 2001). The program insists that all of its components are faithfully implemented with several elements referred to as being non-negotiable. The premise of CLaSS is that through changing individual teacher's practices student learning outcomes can be improved in significant and enduring ways. 
As with other education reform programs originating out of a socio-political environment dominated by neo-liberal perspectives, the way teachers go about their work is the centre of attention, and modifying teachers' behaviour is crucial to the success of the program. The analysis proposed in no way disparages CLaSS itself, nor does it seek to judge its objectives, or offer a critique of the specific methods used to improve literacy. Rather, it advocates that genuine school improvement requires one to step outside the circle of discourse engendered by reform programs such as CLaSS which promote a 'single minded' discourse about themselves and that which the school is attempting. When programs are introduced into schools as part of a sector-wide reform agenda they are expected to provide proof of improved results in order to justify the financial investment associated with the initiative. The values and beliefs of the reform initiative are expected to be accepted by school systems usually without question (Apple, 2000) and with little or no regard to consequences on teachers' professionalism and how it is practiced.

\section{Problem of Research}

The study reported in this paper is significant because it demonstrates that, by opening the scrutiny the reality of lived experiences of principals, alternative analyses of reform programmes can occur. The purpose of this study is to investigate the impact of a neo-liberal school reform on conceptions of principals' work and leadership. Discourse analysis is promoted as a useful methodology in determining the broader effects of neo-liberal reform in schools and report on the value of investigating the explanatory frameworks, work stories, used by school principals in exploring the effects of a neo-liberal reform program in their schools.

\section{Methodology of Research}

\section{Discourse Analysis}

Discourse analysis provides insights beyond the institutional context of schools. One feature of discourses is that they make possible to speak and understand some issues and at the same time exclude other discourses (Hall, 1992). Ball (1994) argues that "discourses are about what can be said, and thought, but also about who can speak, when, where and with what authority" (p. 21). The institutional parlance that comes with neo liberal reform is often non-contradictory and homogenous (Humes, 2000; Jokinen \& Juhila, 1993). The dominant discourse of neo-liberal reform is legitimated as a series of self-evident, natural and unquestionable truths (Jokinen \& Juhila, 1993) and may become so strong that it precludes other possible discourses and is difficult to refute (Fairclough, 1992, 1995; Foucault, 1969). In essence, the ideological context of the reform program controls the construction of a narrative that presents a preferential account of what happens in the school (Humes, 2000).

According to Gee (2005) discourses present themselves as "theories (images, explanatory frameworks) that people hold, often unconsciously, and use to make sense of the world and their experiences of it." In their accounts the principals constructed their version of being a principal in a CLaSS school. These accounts were built on available resources, including the reform program documentation and associated training as well as the principal's personal and professional history (Potter \& Wetherell, 2001). The principal's accounts were narratives of themselves and their relationships with the teachers, parents and students (Gergen, 2001). To capture the constructive and narrative nature of the accounts, the concept of the work story was used. In their work stories the principals identified and justified themselves and defined CLaSS as their school practice. They demonstrated how they interpreted their role and explained the implementation and maintenance of the program. 
John RAFFERTY, Tuija A. TURUNEN. Principals' work stories within neo-liberal school reform

PROBLEMS

OF EDUCATION

IN THE $21^{\text {st }}$ CENTURY

Volume 64,2015
Instrument and Procedures

The data were gathered over a six month period in semi-structured interviews with principals of four CLaSS-schools in Australia. Principal A led a school with approximately 200 students in a rural town. By the time of the interview the school had been involved with the program for three years. Principal B was the head of a rural school with approximately 180 students. This school had been part of CLaSS since 1999 and had a long history of implementing the programme. Principal C's school was located in a large regional centre and had a student enrolment of 385 students. Also, this school had been part of CLaSS since 1999. Principal D led a big school with 470 students in a provincial city. Similar to schools B and C, this school had been part of CLaSS since 1999 and the principal joined it in 2000 when the school was in its second year of the programme. All four schools saw themselves as CLaSS-schools and the principals shared the beliefs and understandings that are fundamental to CLaSS.

In the interviews the principals were invited to discuss the reasons why their school had engaged CLaSS, what was required to maintain CLaSS and what difference CLaSS had made to the school. Each participant was asked a series of questions during the interview. Interviewees were given the same questions, but they were not structured or ordered in the same way. The interview questions were:

1. The CLaSS documents talk directly about the role of the principal as a motivator, and about enduring through the hard times. Were there hard times during the implementation of CLaSS here?

2. What would you do in the face of strong or enduring resistance?

3. Have any teachers wavered with their support? If so, how is this (or would this be) handled?

4. What would happen if a cluster of school said they are dropping CLaSS?

5. The two hour literacy block seems to be quite rigid and structured. What would you imagine a classroom would look like during this time?

All interviews were recorded digitally to maintain the flow and pace of the interview. Transcripts were drawn from recordings and entered to qualitative analysis software NVivo. This software was used as an interactive electronic database that provided instrumentation for the comprehensive coding of data which facilitated deep levels of analysis.

\section{Data Analysis}

Data analysis followed the phases of reduction, display and conclusion drawing/verification (Huberman \& Miles, 1998). Data reduction included coding, clustering and data summaries, which were then transformed into themes. Conclusions were drawn by noting patterns within themes, seeing plausibility, making contrasts, comparisons and metaphors, and clustering by conceptual grouping (Huberman \& Miles, 1998).

Through the analysis it became apparent that the work stories occupied 'spaces' that existed between the dominant discourse and a lived reality of the school. They highlighted and legitimated the principals' accounts of what had changed in their schools as a result of engaging the reform. The work stories included several sub-themes, story lines. Table 1 identifies how the story lines of the principals' work stories influenced their constructions of implementing CLaSS. In the table, the story lines are accompanied by catchphrases of the work stories to articulate the core messages. 
Table 1. Story lines in the principals' work stories.

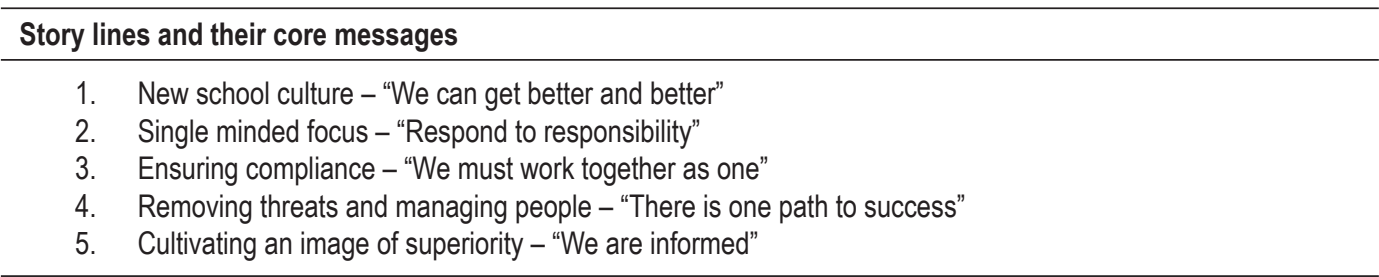

From a neo-liberal perspective these story lines can be interpreted as reasonable and rational guidelines which the principals used to motivate their school communities to move harmoniously toward improvement. But, they can also be used with a firmness of purpose to establish social norms and ensure conformity of teacher behaviour. The following section outlines the each story line.

\section{Results of Research}

\section{New School Culture}

The principals explained how CLaSS had provided an appropriate response to what they considered to be the flawed culture of their respective schools. The principals demonstrated the need and their own capacity to be single minded in their focus on improving the school through implementing CLaSS. They raised issues, demonstrating their commitment to ensuring the extensive financial and human resources needed to implement CLaSS. The principals were firm in their belief that CLaSS will be successful if the school could implement the program as directed, without alteration of any kind. They indicated that ensuring total compliance to the CLaSS design was achieved through acknowledging that the culture within the school, prior to implementing CLaSS as being fundamentally flawed. The principals prioritized the development of a new culture within the school:

We need to stick with other ClaSS schools and see what they are doing well and keep improving ourselves. This is probably the area we got the most ouf of anyway-our teachers'visiting other CLaSS schools was fantastic professional development. There are a couple of schools that do CLaSS really well and we try to visit them often. (Principal A)

When the four principals referred to a flawed culture in their schools, they did not criticize individual teachers or point to bad practices that had crept into teachers' professional lives. The term "flawed culture" was the platform used by the authors of CLaSS and by those who had been inducted into CLaSS thinking as a way of suggesting that there was a single way of acting and thinking that could be adopted. The principals selected the right team and engaged various control technologies to ensure their ongoing compliance. The effect of this action has allowed schools to cultivate a new image for themselves and promote a new professional identity among the staff. It is accepted by these principals that CLaSS is their preferred model of whole school reform.

Our whole teaching and learning policy and culture now is based around the CLaSS design.

\section{(Principal B)}

During the interview Principal A stated several times that CLaSS was a vehicle to bring about a "change in the culture of the school concerning teaching and learning". The other principals also talked about CLaSS as a way to new, better school culture. 
John RAFFERTY, Tuija A. TURUNEN. Principals' work stories within neo-liberal school reform

PROBLEMS

OF EDUCATION

IN THE $21^{\text {st }}$ CENTURY

Volume 64, 2015

80

It is about accountability. If you want funding, you need to prove the effectiveness of programs - CLaSS schools can do this. (Principal C)

Principal D specially identified his school as fundamentally flawed in its approach to teaching literacy, and saw the emergence of a "new culture" as required, if any improvement was to occur:

So, we thought, well yes, if we can get this conversation happening and we can dedicate time in the school to doing literacy properly and we can all use a common language and we are approaching it together, there must be hope of some improvement and change. (Principal D)

\section{Single Minded Focus}

The principals referred to their own critical role developing the "new culture". Aspects of CLaSS were non-negotiable and had to be implemented. Principal B regarded such aspects of CLaSS as pivotal in establishing a mutually supportive environment within the school community. In turn, such mutual support added strength to the single-minded approach needed to implement and maintain CLaSS:

The key to it all, a non-negotiable element of CLaSS is that the principal and the CLaSS coordinator have to give strong leadership and some co-ordination to it. (Principal B)

For principals, CLaSS was the only valid approach to meeting children's individual literacy needs. The successful implementation of CLaSS required a single-minded approach to ensure that the whole school community was committed to it. This single-mindedness was about leadership, like leadership in a business corporation - sticking to goals, establishing corporate identity, strategic planning, keeping everyone on task, focusing on production and meeting outputs, keeping to budget and being accountable for results. Principal B stated clearly that the role of the principal was to be focused totally on the objectives of CLaSS. According to Principal B nothing other than a single-minded approach was needed for CLaSS to be maintained. He was adamant that he cannot be seen to back-off from his personal commitment to CLaSS. He was the corporate leader:

Every day, I do the principal walk through classrooms.... If I back off, it sends a subtle message to teachers that we have implemented a design that you can be half-hearted about. (Principal B)

The principal walk referred to above was a feature of CLaSS and the purpose of the walk was not to look at children's work; rather it was to be seen in the work place. As a corporate leader the principal could not be an office person. The principal walk was also important for making sure that things were going smoothly and according to plan. As one principal commented:

C)

If I see someone doing something different I can have a conversation with them. (Principal

All the principals made a reference to the value of weekly meetings in revitalizing the staff commitment to CLaSS and regarded the effort involved as tangible evidence of the "single-mindedness' of the staff:

That's why we need to constantly keep meeting and talking about what should be happening in our classrooms. That tends to revitalize teachers and keep them on a steady flow. (Principal A) 
The principals stated that nothing within the school curriculum was more important than the attainment of improved literacy outcomes for their students. The language in which this commitment was expressed was the language of the corporate team leader:

It [CLaSS] is a great selling point when you walk in with people through our school especially if they're prospective enrolments. (Principal B)

It was also the language of the sporting coach:

Teachers have been trained hard and sacrificed their individuality for the good of the team, but it has all been worthwhile. (Principal C)

So eventually the teachers were mentally tired. Physically, they were tired. We are very much aware of how tiring CLaSS can make teachers. But considering the results at the end of the school year, everyone thinks it is worth the effort. (Principal, D)

The decisions that principals made to achieve this priority were shaped by corporatist beliefs and values. As they described their roles in supporting CLaSS and the decision they had taken, there was little reference to educational considerations. While the principals did mention that their commitment to CLaSS was driven by a desire to ensure that individual children were not left behind educationally, the focus was on literacy attainment according to the narrow measures provided by CLaSS. Reflection and discussion on the nature and quality of children's literacy, diverse literacies, quality of teaching and of student work were absent from the principals' comments. It was more about branding, team leadership, maintaining morale and achieving improved outcomes.

\section{Ensuring Compliance, Removing Threats and Managing People}

The needs of the students through ensuring that CLaSS is faithfully implemented were unapologetically given priority over all other needs, particularly the needs of the staff. The value of a staff member could be determined by the contribution that she or he could make to the program. Staff who did not comply was seen as threats and were strategically re-assigned within the school. There was no room for discontent or wavering support of CLaSS. As Principal A explained:

We state we are committed to excellence in teaching and learning... anything less is not good enough... CLaSS provides a path to excellence in literacy development, we are committed to it... we push this really hard. (Principal A)

For all the principals any incidence of wavering was swept aside through the commitment to follow the "path to excellence" as prescribed by CLaSS. Within the CLaSS team there was no room for discontent or deviation. When asked to describe his likely response to a hypothetical staff member beginning to lose faith in CLaSS Principal A indicated:

I would go back and revisit the reasons why we are doing CLaSS with that person. The reason is to enhance the literacy standards of the children and the whole community agreed to take on CLaSS. We have no excuses, we know CLaSS works and we are committed to it for the betterment of the children. It would be a difficult point to argue against. (Principal A)

The argument was directed to a hypothetical staff member and the extrapolation was "therefore you have agreed" and "therefore you have to be on board as well". Indeed, it would be difficult for a teacher to "argue against" such a position expressed so forcefully and cogently by the principal. The principals vigorously defended and promoted their commitment to CLaSS 
John RAFFERTY, Tuija A. TURUNEN. Principals' work stories within neo-liberal school reform

PROBLEMS

OF EDUCATION

IN THE $21^{\text {st }}$ CENTURY

Volume 64, 2015

and associated commonalities by engaging what can be described as 'control technologies'. All four principals told about a range of 'control technologies' including their own physical presence in classrooms, direct "dialogue" with staff, devolution of authority (mostly to the CLaSS coordinator) and overt reliance on visual and verbal clues to ensure that commonality in ideology and language was pursued, even policed if necessary. Non-compliance or rebelliousness to the conventions of CLaSS by teachers was treated procedurally within the context of the desired outcomes by the principal.

\section{Cultivating an Image of Superiority}

While acknowledging similarities with other literacy programs, the four principals maintained that there were important differences between CLaSS and non-CLaSS schools. Engaging in CLaSS was proof of heightened awareness and understanding about the very nature of teaching and learning, resulting in a shared understanding and a common purpose among the entire school community. When people, parents in particular, perceived diversity in teachers' approaches to literacy, this was seen, especially by the principals, as an undesirable characteristic that should be replaced with consistency. CLaSS was described as a "great equalizer", and dominated the approach these schools take to literacy. According to the principals, CLaSS made them different from, and better than, other schools. When asked to comment on factors that differentiate CLaSS from other reform programs, Principal B explained:

Only the CLaSS model actually ensures that each of those components needed for reform happen. The principal gets CLaSS professional development; the CLaSS coordinator gets ongoing professional development and the teachers get professional development. All this together combines to ensure that we all walk the right path. Where CLaSS professional development is concerned and our understanding about literacy is concerned, we all hear the same thing. (Principal B)

"Hearing the same thing" and "walking the same path" provided Principal B with the catalyst to promote the school as being in control of literacy. The combination of certainty, decisiveness in regard to communicating to parents, and the confidence that came from being in control of literacy were the most distinguishable and defining aspects of CLaSS. Principal D claimed that from his perspective:

It's okay for schools to do whatever they want in literacy. If schools are comfortable with knowing where their kids are starting from and can show how the kids have improved, schools can do whatever they like. Now, I'm sceptical as to whether every school is being able to do that with their kids. (Principal D)

This intense focus on image and marketing did not necessarily mean the schools had spent time discussing educational perspectives on literacy among staff. In any event, the CLaSS documentation regarded discussions on issues to do with the educational perspectives on literacy as an unnecessary professional liberty; the "hard work" has already happened among the experts. Educational discussions concerning the philosophy and pedagogy of literacy would have inevitably introduced elements of ambiguity and complexity to the school community. Such notions were unhelpful in the cultivation of images that CLaSS principals wanted to convey. In any case, the CLaSS program removed ambiguity and complexity. Failure is not an option for a CLaSS school. By following the program they could rest assured that all their students can and will achieve high standards of literacy. 


\section{Discussion}

As the results of this study demonstrated, the principals' work stories were active and had functions. They made things happen and had practical implications which produced subject positions for the principals themselves and the teachers in their schools (Davies \& Harre, 2001; Taylor, 2001). For example, the teachers had to be managed and controlled carefully through a series of control technologies. The value of a teacher could be determined by their compliance to the imperatives of the reform. CLaSS effectively prescribed the purpose of the school, the instructional behaviour of the teachers and the structure of learning experiences. To not fully comply with CLaSS was to be oppositional to the new culture of the school. Proponents of neo-liberal reform may argue that this was a reasonable position for the school to take. However, such a position predicated significant changes to the professional practice and identity of the principals and teachers. They became 'managed professionals' with diminished trust and respect as teaching and education professionals (Codd, 2005).

Further, it can be argued that the principal had to take the role of the corporate leader as opposed to that of an educational leader. As Hill and Crévola (2001) contend, the educational direction of the school has been developed by the experts. The principals' primary role was to ensure the best practices defined by the reform were adequately resourced and faithfully implemented. Again, it could be argued that such a role was appropriate or even desirable. After all, educational policies will continue to place ever increasing demands on schools, school systems, principals and teachers to provide evidence of improvement in student outcomes and for schools to behave in business like ways. However, such redefining of principals' and teachers' professionalism, and how it is practiced, had a significant impact on schools.

These redefinitions were incorporated into schools and used, without question. Ongoing questions such as, "How probing or searching is our definition of literacy?"; "What kind of literacy will our children need in the $21^{\text {st }}$ century?"; "Are there forms of literacy, we need to consider more deeply such as designing a website?"; "Who is deciding what is or is not appropriate and from what framework do we draw our conclusions?"; "What distinguishes teachers from other workers?", were no longer central to the discourse of reform in the sense that they had already been answered by the program. The energy needed to sustain such questions and subsequent debate was better spent getting on with the work of improving children's outcomes (Hill \& Crévola, 2001).

\section{Conclusions}

Using discourse analysis to construct work stories opens up the rationalities behind the curriculum and school reforms and allows the previously unseen perspectives to be considered. Work stories help to understand what is happening to particular individuals within particular institutions at particular times. Within the neo-liberal landscape there is a temptation to think that the social relations, meanings and assumptions of schooling are no longer problematic. This paper demonstrates that, by opening to scrutiny the reality of the lived experiences of educators, alternative analyses of reform programs can occur. Through the work stories the reality of these experiences in schools can be examined. If education is to be connected to the lived realities of schools, teachers, students and communities, the production and circulation of discourse, and their effects on the lives of people, is of critical importance. Discourse analysis provides opportunities for the previously unheard and sometimes silenced perspectives of those who are involved with the day-to-day implications of reform programs to become clearly audible. Potentially important perspectives that are both unintentionally and intentionally obscured by the dominant discourse are given a platform from which to be recognized.

It is reasonable to expect that neo-liberal inspired educational policies will place ever increasing demands on schools, school systems and teachers to provide evidence of improvement in student outcomes and for schools to behave in business like ways. The expectation for 
John RAFFERTY, Tuija A. TURUNEN. Principals' work stories within neo-liberal school reform

PROBLEMS

OF EDUCATION

IN THE $21^{\text {st }}$ CENTURY Volume 64, 2015

84

schools and teachers to respond to educational issues through neo-liberal notions of measurement, accountability and performativity is likely to continue. As schools search for a response to this ideological pressure, neo-liberal reform programs like Class will become increasingly attractive. The guarantees that the programs offer schools in regard to responding to neo-liberal demands, is difficult to ignore. However, as this study demonstrated, within the neo-liberal dominated landscape time for principals and teachers to think and talk about their practices and the purpose of schooling with professional autonomy, is regarded as an intolerable and unproductive extravagance that schools can no longer afford. In order for authentic reform to occur, it is essential that schools retain an awareness of all the outcomes associated with engaging reform programs. To do this, school administrators, principals and teachers need the tools and skills to allow them to see the reality that lies beyond the rhetoric of individualism and accountability. This requires open discussions and time to re-think educational practices and programmes.

\section{References}

Apple, M. W. (2000). Between neoliberalism and neoconservatism: Education and conservatism in a global context. In N. C. Burbules \& C. A. Torres (Eds.), Globalization and Education: Critical Perspectives (pp. 57-78). New York: Routledge.

Apple, M. W. (2004). Ideology and curriculum (3rd Ed.). New York: Routledge Falmer.

Australian Curriculum Assessment and Reporting Authority ACARA. (2008). National Assessment Program - Literacy and Numeracy, NAPLAN. Retrieved 07/06, 2012

Ball, S. J. (1994). Educational reform. A critical and post-structural approach. Buckingham: Open University Press.

Ball, S. J. (2004). Performativities and fabrications in the education economy: Towards a performative society. In D. Gleeson \& C. Husbands (Eds.), The performing school: Managing, teaching and learning in a performance culture (pp. 169-182). London: Routledge.

Codd, J. (2005). Teachers as 'managed professionals' in the global education industry: The New Zealand experience. Educational Review, 57 (2), 193-206.

Crévola, C., \& Hill, P. (2005). The children's literacy success strategy (CLaSS). A research report on the first six years of a large-scale reform initiative. Melbourne: Catholic Education Commission of Victoria.

Davies, B., \& Harre, R. (2001). Positioning: The discursive production of selves. In M. Wetherell, S. Taylor \& S. J. Yates (Eds.), Discourse theory and practice. A reader. (pp. 261-271). London: SAGE.

Department of Education, Employment and Workplace Relations DEEWR. (2008). Smarter schools National partnership. Canberra.

Desimone, L. (2002). How Can Comprehensive School Reform Models Be Successfully Implemented? Review of Educational Research, 72 (3), 433-479. doi: 10.3102/00346543072003433.

Elliott, B., \& Maclennan, D. (1994). Education, modernity and neo-conservative school reform in Canada, Britain and the US. British Journal of Sociology of Education, 15 (2), 165-185.

Elmore, R. F. (2000). Building a new structure for school leadership. Washington, DC: The Albert Shanker Institute.

Fairclough, N. (1992). Discourse and social change. Cambridge: Polity Press.

Fairclough, N. (1995). Critical discourse analysis. The critical study of language. London: Longman.

Foucault, M. (1969). Tiedon arkeologia [The archaeology of knowledge] (T. Kilpelainen, Trans.). Tampere, Finland: Vastapaino.

Fullan, M. (2007). The new meaning of educational change (4 Ed.). New York: Teachers College Press.

Fullan, M. (2009). Large scale reform comes to life. Journal of Educational Change, 10 (2), 101-113.

Fullan, M., Bertani, A., \& Quinn, J. (2004). New lessons for district reform. Educational Leadership, 61 (7), 42-46.

Fullan, M., Hill, P., \& Crevola, C. (2006). Breakthrough. California: Corwin Press.

Gee, J. P. (2005). An introduction to discourse analysis theory and method. New York: Routledge.

Gergen, K. (2001). Self-narration in social life. In M. Wetherell, S. Taylor \& S. J. Yates (Eds.), Discourse theory and practice. A reader (pp. 247-260). London: Sage.

Goldstein, H., \& Myers, K. (1997). School effectiveness research: A bandwagon, a hijack or a journey towards enlightenment? Education-line. 
Gruenewald, D. A. (2004). A Foucauldian analysis of environmental education: Toward the socioecological challenge of the Earth Charter. Curriculum Inquiry, 34 (1), 71-107.

Hall, S. (1992). The West and the rest: Discourse and power. In S. Hall \& B. Gieben (Eds.), Formations of modernity (pp. 275-331). Cambridge: Polity Press.

Harris, A., \& Chrispeels, H. (2006). Improving schools and educational systems: International perspectives. London: Routledge.

Her Majesty's Government. (2006). Higher standards, better schools for all. White paper. London: Stationery Office.

Hill, P., \& Crévola, C. (2001). Children's literacy success strategy: An overview. Melbourne: Catholic Education Office.

Huberman, A. M., \& Miles, M. B. (1998). Data management and analysis methods. In N. K. Denzin \& Y. S. Lincoln (Eds.), Collecting and Interpreting Qualitative Materials (pp. 179-210). Thousand Oaks, CA, USA: Sage.

Humes, W. (2000). The discourses of educational management. Journal of Educational Enquiry, 1 (1), $35-53$.

Jeffrey, B. (2002). Performativity and primary teacher relations. Journal of Educational Policy, 17 (5), 531-546.

Jokinen, A., \& Juhila, K. (1993). Valtasuhteiden analysoiminen [Analyzing power relationships]. In A. Jokinen, K. Juhila \& E. Suoninen (Eds.), Diskurssianalyysin aakkoset [Alphabets of discourse analysis] (pp. 75-108). Tampere, Finland: Vastapaino.

Levin, B. (2010). The challenge of large-scale literacy improvement. School Effectiveness and School Improvement, 21 (4), 359-376.

Levin, B., \& Fullan, M. (2008). Learning about system renewal. Educational Management Administration \& Leadership, 36, 289-303.

Matthews, R. J., O’Mahony, G. R., \& Barnett, B. G. (2006). Managing change: Leading school improvement. Victoria, Australia: Hawker Brownlow Education.

Popkewitz, T. (2008). Cosmopolitanism and the age of school reform. London: Routledge.

Potter, J., \& Wetherell, M. (2001). Unfolding discourse analysis. In M. Wetherell, S. Taylor \& S. J. Yates (Eds.), Discourse theory and practice. A reader. (pp. 72-81). London: Sage.

Rafferty, J. (2008). The emergence of a dominant discourse associated with school programs: A study of CLaSS. (Doctor of Education), Australian Catholic University, Melbourne.

Rafferty, J. (2010). The realities of school reform: The effects of managerial discourse on the work of teachers, principals, and on school improvement. Saarbrucken, Germany: Lambert Academic Publishing.

Taylor, S. (2001). Locating and conducting discourse analytic research. In M. Wetherell, S. Taylor \& S. J. Yates (Eds.), Discourse as data. A guide for analysis (pp. 5-48). London: SAGE.

Turunen, T. A., \& Rafferty, J. (2013). Insights beyond neo-liberal educational practices: The value of discourse analysis. Educational Research for Policy and Practice, 12 (1), 43-56.

Advised by Vincentas Lamanauskas, Šiauliai University, Lithuania

Received: January 29, 2015

Accepted: April 16, 2015

\begin{tabular}{l} 
PROBLEMS \\
OF EDUCATION \\
IN THE 21 $1^{\text {st }}$ CENTURY \\
Volume 64, 2015 \\
\hline 85
\end{tabular} 